\title{
Behavioral Economic Measures of Alcohol Reward Value as Problem Severity Indicators in College Students
}

\author{
Jessica R. Skidmore ${ }^{1,2}$, James G. Murphy ${ }^{1}$, and Matthew P. Martens ${ }^{3}$ \\ ${ }^{1}$ The University of Memphis \\ 2University of California, San Diego \\ ${ }^{3}$ University of Missouri
}

\begin{abstract}
The aims of the current study were to examine the associations among behavioral economic measures of alcohol value derived from three distinct measurement approaches, and to evaluate their respective relations with traditional indicators of alcohol problem severity in college drinkers. Five behavioral economic metrics were derived from hypothetical demand curves that quantify reward value by plotting consumption and expenditures as a function of price, another metric measured proportional behavioral allocation and enjoyment related to alcohol versus other activities, and a final metric measured relative discretionary expenditures on alcohol. The sample included 207 heavy drinking college students (53\% female) who were recruited through an oncampus health center or university courses. Factor analysis revealed that the alcohol valuation construct comprises two factors: one factor that reflects participants' levels of alcohol price sensitivity (demand persistence), and a second factor that reflects participants' maximum consumption and monetary and behavioral allocation towards alcohol (amplitude of demand). The demand persistence and behavioral allocation metrics demonstrated the strongest and most consistent multivariate relations with alcohol-related problems, even when controlling for other well-established predictors. The results suggest that behavioral economic indices of reward value show meaningful relations with alcohol problem severity in young adults. Despite the presence of some gender differences, these measures appear to be useful problem indicators for men and women.
\end{abstract}

\section{Keywords}

Behavioral economics; Alcohol-related problems; Alcohol use; College students

Correspondence concerning this article should be addressed to Jessica R. Skidmore, Department of Psychiatry, University of California, San Diego, 8950 Villa La Jolla Dr B-218, La Jolla, CA 92037. jessica.rose.skidmore@ gmail.com Phone: (858) 822-0478 Fax: (858) 642-3557.

Jessica R. Skidmore, Ph.D., Department of Psychology, The University of Memphis; James G. Murphy, Ph.D., Department of

Psychology, The University of Memphis; Matthew P. Martens, Ph.D., Department of Educational, School, and Counseling

Psychology, University of Missouri.

Jessica R. Skidmore is now at University of California, San Diego.

All authors contributed to the manuscript significantly and have read and approved the final manuscript.

The authors have no conflicts of interest to disclose. 
Behavioral economic (BE) research on substance abuse attempts to study patterns of drug and alcohol use as they develop and change over time in the context of changes in access to substances and other activities (Murphy, Correia, Colby, \& Vuchinich, 2005; Tucker, Roth, Vignolo, \& Westfall, 2009). BE models of addiction have demonstrated significant breadth and utility in guiding research ranging from basic laboratory research to prevention, treatment, and policy research, and these measurement models may provide important insight into the apparent irrationality of addictive disorders (Bickel, Johnson, Koffarnus, MacKillop, \& Murphy, 2014; Heinz, Lilje, Kassel, \& deWit, 2012). BE theory predicts that the potential for substance abuse is highest when an individual values substance-related rewards more than the rewards associated with available substance-free activities (Rachlin, 1997). Thus, a key challenge for BE approaches to assessment is to quantify the relative value of drug-related rewards.

There are several BE measures that have proven useful for understanding drug selfadministration in laboratory models (Bickel, Marsch, \& Carroll, 2000) and have more recently been translated into self-report measures that can be administered in clinical settings (Bruner \& Johnson, 2013; Murphy, MacKillop, Skidmore, and Pederson, 2009; Tucker et al., 2009). These approaches to understanding individual differences in alcohol reward value have the potential to advance BE models of addiction (Bickel et al., 2012; Stanger, Budney, \& Bickel, 2012; Vuchinich \& Heather, 2003) and might also increase understanding of the nature of incipient alcohol problems in heavy drinking young adults who are at high risk of developing future alcohol use disorders (AUDs; O'Neill \& Sher, 2000; Vik, Carrello, Tate, \& Field, 2000).

\section{Behavioral Economic Demand Curve Indices}

Demand curves plot consumption as a function of price and can be used to measure an individual's demand for alcohol. Expenditure curves are plotted by multiplying an individual's reported consumption at each price by the specific price, and plotting the resulting expenditures as a function of drink price. Researchers have developed hypothetical alcohol purchase tasks for use with clinical samples and there is evidence that these tasks yield five reliable and valid individual difference measures of alcohol demand or reward value: intensity, $\mathrm{O}_{\max }, \mathrm{P}_{\max }$, breakpoint, and elasticity (Amlung, Acker, Stojek, Murphy, \& MacKillop, 2011; Jacobs \& Bickel, 1999; Kiselica \& Borders, 2013; MacKillop \& Murphy, 2007; Skidmore \& Murphy, 2010). Intensity is consumption when drink price is zero, and provides a measure of free-access demand for alcohol. $\mathrm{O}_{\max }$ is maximum expenditure, and $\mathrm{P}_{\max }$ is the price associated with $\mathrm{O}_{\max }$, as well as the price at which demand becomes elastic. Breakpoint is the price at which consumption equals zero, and thus the point at which demand is completely suppressed. Elasticity of demand is the rate at which demand for a reinforcer decreases as a function of price and therefore quantifies the relative sensitivity of consumption to price. Hursh and Silberberg (2008) suggest that elasticity may reflect the "essential value" of a commodity by scaling its relative price sensitivity. In sum, alcohol purchase tasks estimate alcohol reward value by identifying how much someone would drink given unrestricted (free) access to alcohol, how much they would spend on alcohol, and the extent to which their consumption level is price sensitive. 
Factor analytic studies suggest that the five metrics form two latent factors, but that the factors do not demonstrate a simple structure. Amplitude, which represents the maximum spent and consumed, is composed of intensity and $\mathrm{O}_{\max }$, and Persistence, which represents the sensitivity to increasing price, is composed of elasticity, $\mathrm{P}_{\max }$, breakpoint, and $\mathrm{O}_{\max }$ (Bidwell, MacKillop, Murphy, Tidey \& Colby, 2012; MacKillop et al., 2009). Persistence metrics may be less directly related to alcohol use than the Amplitude metrics (Yurasek et al., 2011). Intensity, $\mathrm{O}_{\max }$, and breakpoint are positively correlated with drinks per week and alcohol-related problems among college students (Murphy \& MacKillop, 2006; Smith et al., 2010). Also, among adult drinkers intensity is positively correlated and marginally predictive of AUD symptoms and craving for alcohol (MacKillop et al., 2010). Importantly, elevated demand may also be associated with diminished response to brief alcohol interventions. Greater $\mathrm{O}_{\max }, \mathrm{P}_{\max }$, breakpoint, and elasticity values all predicted greater levels of typical weekly drinking six months following a brief intervention, even after controlling for baseline drinking and gender (MacKillop \& Murphy, 2007). Among cocaineindependent individuals elasticity and $\mathrm{P}_{\max }$ are associated with real-world cocaine usage (Bruner \& Johnson, 2013). Thus, even within samples of regular drinkers or substance users, individual differences in demand may reflect the propensity for problems and substance use patterns that are relatively impervious to intervention.

\section{Relative Behavioral Allocation and Enjoyment}

Naturalistic studies using human participants often measure alcohol reinforcement or value by some combination of activity participation and enjoyment ratings (Correia, Carey, Simons, \& Borsari, 2003; Correia, Simons, Carey, \& Borsari, 1998; Skidmore \& Murphy, 2010). Reinforcement survey instruments typically define reinforcement as the product of activity frequency and enjoyment ratings, and addiction researchers have modified these measures to separate substance-related and substance-free reinforcement (Correia et al., 1998). Correia and colleagues (1998) found that a matching law (Herrnstein, 1970) based measure of the ratio of substance-related to total reinforcement was correlated with and significantly predictive of substance use days. This measure provided an index of the relative value of alcohol compared to substance-free activities. The brief alcohol intervention study described previously (Mackillop \& Murphy, 2007) found that, similar to the demand curve measures of alcohol reward value, this relative substance-related reinforcement ratio $(\mathrm{RR})$ predicted drinking at 6-month follow-up, even after controlling for baseline drinking. Thus, participants who, prior to treatment, had a number of enjoyable alternatives to drinking, were more likely to reduce their drinking following an intervention than participants with similar drinking levels but greater proportional reinforcement related to alcohol.

\section{Relative Monetary Expenditures on Alcohol}

Another way to assess the value of alcohol is to examine actual patterns of monetary expenditures for alcohol over time. Tucker and colleagues (2002, 2006, 2008, 2009, 2012) conducted a series of studies to examine the Alcohol-Savings Discretionary Expenditure Index (ASDE) and its relations to recovery from alcohol dependence. The ASDE measures the difference between relative discretionary expenditures towards alcohol and relative 
discretionary expenditures towards savings. Savings is used in order to capture relative preference for alcohol (an immediate reinforcer) versus the delayed reinforcement associated with monetary savings. Larger ASDE values reflect greater valuation of alcohol relative to savings and have been shown to predict unstable drinking patterns following alcohol problem resolution, even after controlling for other significant measures of problem severity and resolution type (e.g., natural recovery, informal self-help, formal treatment; Tucker et al., 2002; 2006). The ASDE, like the demand curve and RR indices, may provide a clinically relevant index of alcohol value that is associated with greater problem severity and poor treatment response.

\section{College Drinking}

As many as $18 \%$ of college students met diagnostic criteria for alcohol abuse or dependence in the past year, suggesting that there is a relatively high rate of clinically significant alcohol problems in this population (Slutske, 2005). Although many college students eventually moderate their alcohol use on their own (Jackson, Sher, Gotham, \& Wood, 2001), the high rate of alcohol use and related-problems poses a significant public health problem and places college students at risk for future AUDs. In fact, college students face a variety of consequences from their drinking ranging from missed classes and hangovers to more severe consequences such as blackouts and drunk driving (Hingson, Zha, and Weitzman, 2009; National Institute on Alcohol Abuse and Alcoholism, 2012). Given the high base-rate of heavy drinking and alcohol problems in this population, there is a need for more specific and theoretically based measures of alcohol problem severity. BE indices that capture the relative value or motivational salience of alcohol are based on well-developed theory and empirical laboratory research and may hold promise in this regard (Gentile, Librizzi, \& Martinetti, 2012).

Although the BE metrics may be appropriate supplemental problem indicators it is also important to assess their predictive utility above and beyond other identified predictors. Protective behavioral strategies are one robust predictor of alcohol problems (Pearson, 2013). These strategies can include alternating between alcoholic and non-alcoholic beverages, using a designated driver, and avoiding drinking games. College drinkers who engage in fewer protective behaviors are at greater risk of experiencing alcohol-related problems (Martens, Martin, Littlefield, Murphy, \& Cimini, 2011). Next, behavioral and biological indicators of impulsivity-related traits, such as sensation seeking, are associated with risky behaviors, and play a role in the initiation and maintenance of alcohol use, alcohol-related problems, and AUD diagnoses (Ham \& Hope, 2003; Lejuez et al., 2010). Finally, there is a positive association between heavy drinking and depression in college students (O'Donnell, Wardle, Dantzer, \& Steptoe, 2006; Paschall, Freisthler, \& Lipton, 2005) and, among heavy drinking college students, those with depressive symptoms experience more alcohol-related problems (Dennhardt \& Murphy, 2011).

\section{Relations among Behavioral Economic Measures}

Although several preliminary studies indicate that BE measures are associated with various aspects of alcohol problem severity (Correia et al., 1998, 2003; MacKillop \& Murphy, 2007; 
Murphy \& MacKillop, 2006; Tucker et al., 2002, 2006, 2008, 2009), only one study has included all of the indices to determine their degree of overlap and the relative strength of associations with traditional measures of alcohol problem severity. Murphy et al. (2009) conducted a pilot study $(N=38)$ that examined the convergent validity of the following metrics: intensity, breakpoint, $\mathrm{O}_{\max }, \mathrm{P}_{\max }$, elasticity, $\mathrm{RR}$, and a relative alcohol-related monetary expenditures measure modeled after the ASDE. Many of the measures of value demonstrated associations with each other, but of varying sizes, suggesting that though the measures are related, the underlying construct may be multifaceted. Intensity, $\mathrm{O}_{\max }$, elasticity, RR, and relative discretionary expenditures on alcohol (RDEA) all demonstrated correlations with alcohol use and alcohol-related problems, but only intensity predicted alcohol-related problems.

The relations between RR and RDEA with intensity and $\mathrm{O}_{\max }$ suggest that these variables may constitute a factor similar to Amplitude (MacKillop et al., 2009). Unfortunately, the small sample size prevented a factor analysis and limited the power of regression analyses to identify the unique predictive value of the various metrics. The Murphy et al. (2009) study also did not examine the predictive utility of the BE measures in comparison to other wellestablished risk factors for alcohol use and problems, or examine potential gender differences.

\section{Current Study}

The goals of the current study were to 1) examine the convergent validity of the various alcohol value measures, 2) address the latent factor structure of the underlying constructs, 3 ) assess the utility of these measures and composites of the factors they form as supplemental indicators of alcohol problem severity by assessing their predictive validity for alcohol use and total alcohol-related problems, 4) examine their incremental utility relative to established predictors of alcohol-related problems, and 5) assess gender difference in the measures' predictive utility for alcohol use and related problems.

We hypothesized that the factor analysis would replicate the two factor structure (Amplitude and Persistence) observed by MacKillop et al. (2009) in their analysis of the demand curve metrics, and further hypothesized that RR and RDEA would be associated with the Amplitude factor. We hypothesized that intensity would demonstrate large positive associations with, and the greatest predictive utility for typical weekly drinking and total problems. We expected that breakpoint, $\mathrm{O}_{\max }, \mathrm{RR}$, and RDEA would demonstrate modest positive relations with typical weekly drinking and total alcohol problems. We also expected moderate negative relations between problem severity and elasticity (smaller elasticity values reflects inelastic demand and greater alcohol reward value). Consistent with previous research (Murphy et al., 2009), we expected weaker, and possibly nonsignificant, relations between breakpoint and $\mathrm{P}_{\max }$ and alcohol problems. Finally, because composites often provide more reliable measurement of a given construct, we hypothesized that the composites would show stronger relations with the alcohol outcomes than would the individual constituent indices. 


\section{Method}

\section{Participants}

Participants were 207 college students from a large urban southern university who were recruited for one of two randomized clinical trials for brief alcohol interventions (see Murphy, Dennhardt, Skidmore, Martens, \& McDevitt-Murphy, 2010). Students were eligible for the studies if they reported one or more heavy drinking episode (five/four or more drinks in one occasion for a man/woman) in the past month at the time of screening. Participants were not seeking treatment. Our recruitment strategy was consistent with recruitment strategies in most brief intervention trials for college drinkers given the extremely low rates of help seeking in this population (Buscemi et al., 2010). The mean age of the sample was $19.50(S D=1.99)$ years and $53 \%$ of participants were women. Sixty-five percent of students self-identified as White/Caucasian, 26\% as Black/African American, 4\% as multiethnic, $3 \%$ as Hispanic/Latino, $1 \%$ as Asian, and less than $1 \%$ as American Indian/ Alaska Native.

\section{Procedure}

All procedures were approved by the university's Institutional Review Board. Potential participants completed brief screening measures in the on-campus student health center or in classroom settings and eligible students were invited to participate in the trials. Participants completed the current study measures during an individual research appointment in a university research laboratory prior to any intervention. Participants were assured of confidentiality and received extra course credit or a monetary payment in exchange for their participation.

\section{Measures}

Demand curve metrics-Demand (intensity, breakpoint, $\mathrm{O}_{\max }, \mathrm{P}_{\max }$, and elasticity) was measured with the Alcohol Purchase Task (APT; Murphy \& MacKillop, 2006). Participants were asked to read the description of a hypothetical drinking scenario and report the number of standard drinks they would purchase and consume at 17 different prices, ranging from free to $\$ 20$ per drink. For each price they were prompted with, "How many drinks would you have if they were \$_each (e.g., free, 25 cents, 50 cents)?" Murphy et al. (2009) found that intensity and $\mathrm{O}_{\max }$ demonstrated excellent test-retest reliability $(r \mathrm{~s}=.89$ and .90 , respectively), breakpoint and elasticity demonstrated good test-retest reliability ( $r \mathrm{~s}=.81$ and .75, respectively), and $\mathrm{P}_{\max }$ demonstrated marginal reliability $(r=.67)$. Research has also found strong correlations between hypothetical and actual alcohol purchases during a self-administration period ( $r=.87$; Amlung et al., 2012).

Reinforcement ratio-RR was measured using the Adolescent Reinforcement Survey Schedule - Substance Use Version (ARSS-SUV; Murphy et al., 2005). Participants were provided with a list of 45 activities and asked to rate the frequency of participation and enjoyment associated with each of the activities during the previous 30 days. Each item was administered twice in order to obtain separate substance-related and substance-free scores. Frequency ratings ranged from 0 ( 0 times in the past 30 days) to 4 (more than once a day), and enjoyment ratings ranged from 0 (unpleasant or neutral) to 4 (extremely pleasant). The 
frequency and enjoyment ratings were multiplied to obtain a cross-product score (ranging from 0 to 16) which provides an approximation of obtained reinforcement (Correia \& Carey, 1999). Substance-related and substance-free reinforcement is the mean cross-product score for all substance-related and substance-free items, respectively. RR is obtained by dividing the substance-related reinforcement by the sum of the substance-related and substance-free reinforcement (ranging from 0 to 1 ). Larger values suggest greater reinforcement from substance-related activities. Previous research has demonstrated that these methods provide reliable estimates of participation in activities, are consistent with observer reports of behavior, and that RR is related to actual substance use as well as response to substance treatment (Murphy et al., 2005; MacPhillamy \& Lewinsohn, 1982).

Relative discretionary expenditures on alcohol-RDEA was measured by calculating the proportion of discretionary money participants spent on alcohol relative to all discretionary money available. Consistent with previous research (Murphy et al., 2009) the proportion of discretionary money spent on alcohol relative to total discretionary funds available was expected to serve as an appropriate proxy for ASDE. Participants were asked to respond to the following questions, "How much money did you have available to spend for non-essential items (e.g., clothing, CDs, entertainment, alcohol, eating in restaurants, going to the movies, etc.) during the past month? (Do not include money budgeted for essentials, such as rent, school books, gasoline, utility bills, groceries, etc.)" and, "How much money did you spend on alcohol in the past month (this includes any alcohol that you purchased, regardless of whether or not you consumed the alcohol)?" Past month alcohol expenditures were then divided by past-month discretionary funds available (ranging from 0 to 1). Larger values suggest greater relative valuation of alcohol.

Alcohol use-Alcohol consumption was measured using the Daily Drinking Questionnaire (DDQ; Collins, Parks, \& Marlatt, 1985). The DDQ asks participants to estimate the total number of standard drinks that they consumed on each day during a typical drinking week in the past month. These drinking totals are summed to generate an estimate of typical weekly drinking. The DDQ has been used frequently with college students and is a reliable measure that is highly correlated with self-monitored drinking reports (Kivlahan, Marlatt, Fromme, Coppel, \& Williams, 1990). Additionally, participants reported the number of HDEs they had engaged in during the past month.

Alcohol-related problems-Alcohol-related problems were measured in the past six months using the Young Adult Alcohol Consequences Questionnaire (YAACQ; Read, Kahler, Strong, \& Colder, 2006). The YAACQ is a 49-item self-report measure that dichotomously assesses alcohol-related consequences. In the present study we were interested in examining the total score $(\alpha=.92)$, which provides an overall index of alcohol problem severity. The YAACQ has demonstrated good test-retest reliability $(r=.86$ for the total YAACQ scale) as well as good concurrent validity with motivation to change drinking and predictive validity with frequency of drinking and GPA for college students (Read, Merrill, Kahler, \& Strong, 2007). 
Protective behaviors-Protective behaviors were measured using the Protective Behavioral Strategies Survey (PBSS: Martens et al., 2005). The PBSS assesses strategies designed to control alcohol use and related negative consequences. The measure includes 15-items. Participants are asked to indicate how frequently they use each strategy when using alcohol, with items coded on a six-point scale ranging from one (never) to six (always). Internal consistency in our sample was $\alpha=.83$.

Sensation seeking-Sensation-seeking was measured using the Brief Sensation Seeking Scale-4 (BSSS-4; Stephenson, Hoyle, Palmgreen, \& Slater, 2003). The BSSS-4 contains four items (one from each subscale) from the Brief Sensation Seeking Scale (BSSS), which is a highly reliable and valid eight item measure (Hoyle, Stephenson, Palmgreen, Pugzles Lorch, \& Donohew, 2002). Research has demonstrated that the BSSS-4 is highly correlated $(r=.89)$ with the BSSS and has also demonstrated adequate internal consistency ( $a=.66$; Stephenson, et al., 2003). The item ratings are summed to provide a measure of sensationseeking; higher scores indicate higher levels of sensation-seeking. The internal consistency of the BSSS- 4 was $\alpha=.74$.

Depressive symptoms-Depression levels were assessed using the Center for Epidemiological Studies Depression Scale (CES-D, Radloff, 1991). The CES-D is a 20 item measure that assesses symptoms of depression over the past week. Participants report how frequently they have experienced each symptom over the past week; rarely (less than 1 day), some of the time (1-2 days), occasionally (3-4 days), or most of the time (5-7 days). Higher scores indicate greater depressive symptoms. The CES-D has demonstrated good reliability and validity in general populations (Radloff, 1991). Additionally, the CES-D has demonstrated good sensitivity and specificity for depression among college students (Shean $\&$ Baldwin, 2008). A clinical cut-off score of 16 is used to indicate an individual at risk for depression. Internal consistency of the CES-D was $a=.85$ in our study.

\section{Data Analysis}

Demand curves-Responses on the APT were used to generate separate consumption and expenditure demand curves for each participant. Consumption values are the reported number of drinks a participant would hypothetically purchase/consume at each of the 17 APT prices. The 17 expenditure values were computed by multiplying participants' reported consumption at each price by the specific price. Four of the demand metrics can be directly observed from the data. Intensity is the reported number of drinks consumed when drinks are free. $\mathrm{O}_{\max }$ is the greatest expenditure value. $\mathrm{P}_{\max }$ is the price associated with $\mathrm{O}_{\max }$ and the point at which demand become elastic. Breakpoint is the first price at which reported consumption is zero. Elasticity (a) is the rate at which demand for a reinforcer decreases as a function of price. It is derived from the following exponential equation (Hursh \& Silberberg, 2008):

$$
\ln \mathrm{Q}:=\ln \mathrm{Q}_{0}+\mathrm{k}\left(\mathrm{e}^{-\alpha \mathrm{P}}-1\right)
$$

Where $\mathrm{Q}$ is the amount consumed, $k$ specifies the range of the dependent variable (alcohol consumption) in logarithmic units, and a specifies the rate of change in consumption with 
changes in price (elasticity). The value of $k$ is constant across all curve fits. In this study, $k=$ 2.834, which was the value that was derived when the samples' mean consumption values were fit to Equation 1 and $k$ was allowed to vary in order to converge on the best fit solution. Demand curves were fit according to the Hursh and Silberberg (2008) guidelines using the Excel spreadsheet calculator available through the Institute for Behavioral Resources website (ibrinc.org). When fitting the data to Equation 1, zero values (which cannot be log transformed) were omitted.

Outliers and normality-Outliers were corrected using the method described by Tabachnick and Fidell (2001). For each variable, values that were greater than or equal to 3.29 standard deviations above the mean were Winsorized to be one unit greater than the greatest non-outlier value. Variables that were skewed or kurtotic were transformed prior to analysis when appropriate. Non-transformed variables were used for regression analyses.

\section{Associations among behavioral economic measures of alcohol value and}

alcohol measures-We conducted bivariate correlations to assess the associations among the alcohol value variables, weekly drinking, total problems, and established predictors.

Factor structure among behavioral economic measures of alcohol value-The confirmatory factor analysis was conducted in AMOS. Because the hypothesized factor structure of the behavioral economic measures did not adhere to simple structure, we examined the fit and loadings of the Amplitude and Persistence factors in separate CFA models. $\mathrm{O}_{\max }$, intensity, $\mathrm{RR}$, and RDEA were indicator variables on the Amplitude factor, while $\mathrm{O}_{\max }, \mathrm{P}_{\max }$, breakpoint, and elasticity were indicator variables on the Persistence factor. Maximum likelihood estimation procedures were used for all analyses, and for identification purposes the variance of the latent factor and error terms were set to one. Based upon our findings we calculated composites with unit-weighted $\mathrm{z}$ scores for each factor.

\section{Predictive utility of behavioral economic measures of alcohol value and factor} composites-To assess the utility of the BE metrics and factor composites to predict alcohol use and total problems we conducted hierarchical regressions. For typical weekly drinking, we controlled for gender, age, and ethnicity (White versus non-White) in step one. Each of the value metrics or each factor composite was included in step two. Two follow up regressions were conducted; each included three of the significant BE metric predictors in step two. For total problems we controlled for gender, age, ethnicity (White versus nonWhite), and typical weekly drinking in step one. Each of the value metrics or factor composites was entered individually as step two. A follow-up regression included all significant BE metric predictors in step two. To assess the predictive utility of each of the BE metrics above and beyond well-established predictors of alcohol problems we conducted additional hierarchical regressions. We controlled for gender, age, ethnicity (White versus non-White), and typical weekly drinking in step one. Step two included the identified risk factor (protective behaviors, sensation-seeking, or depression symptoms). Each of the BE metrics or factor composites was entered individually in step three. Finally, to assess gender differences, we also conducted all regression analyses separately for men and women. The 
results of these analyses are presented in the relevant sections, but for brevity the full gender-segregated statistics and tables can be found online as supplemental materials.

\section{Results \\ Demand Curves}

As expected, reported alcohol consumption exhibited a decelerating curve in response to increasing price, and expenditures exhibited the characteristic inverted U-shaped curve. Figure 1 plots mean consumption and expenditures, respectively, across the 17 different prices. The demand-curve equation (Hursh \& Silberberg, 2008) provided an excellent fit for the aggregated data $\left(\mathrm{R}^{2}=.98\right)$ and for individual participant data (mean $\left.\mathrm{R}^{2}=.89\right)$. For seven participants demand curves could not be plotted, due to missing data, no reported consumption, or reported consumption that did not conform to the demand curves. Therefore, elasticity values could not be calculated for these participants or included in the analyses, but the observed BE measures are still included for these participants.

\section{Normality}

Six study variables were significantly skewed or kurtotic (intensity, $\mathrm{O}_{\max }, \mathrm{P}_{\max }$, elasticity, RDEA, typical weekly drinking). Square root transformations successfully normalized all but two of these. Intensity remained slightly kurtotic following a logarithmic transformation (kurtosis $=1.21, S E=.34$ ), and this transformed variable was used for correlation analyses. Neither square root nor logarithmic transformations completely corrected the skewness or kurtosis of elasticity, but the square root transformation yielded the best results (skewness = $1.76, S E=.17$; kurtosis $=6.82, S E=.34$ ) and was included in the correlation analyses.

\section{Sample Characteristics and Gender Differences}

Table 1 presents descriptive statistics on all study variables. For alcohol use and related problems, men consumed more drinks $(M=22.32, S D=15.47, t(205)=6.73, p<.01)$, drank more frequently $(M=3.14, S D=1.75, t(205)=2.55, p=.01)$, and experienced more alcohol-related problems $(M=14.00, S D=9.36, t(205)=2.14, p=.03)$ than women $(M \mathrm{~s}=$ $10.55,2.55,11.45$ and $S D=8.05,1.58,7.62$, respectively). Of the sample, $58.9 \%$ reported using other drugs in the past six months, and there was no statistically significant difference in drug use between men and women. Also, $32 \%$ of the sample reported smoking cigarettes in the past month with no significant differences in smoking between men and women.

Men reported significantly higher values for intensity $(M=12.35, S D=8.02, t(203)=4.45$, $p<.001), \mathrm{RR}(M=.32, S D=.18, t(197)=1.99, p=.05)$, and RDEA $(M=.26, S D=.24$, $t(192)=1.97, p=.05)$ than women $(M \mathrm{~s}=8.33, .27, .21$ and $S D=6.26, .17, .25$, respectively). Women had significantly higher $\mathrm{P}_{\max }$ values $(M=4.36, S D=2.65, t(202)=$ $-2.48, p=.01)$ than men $(M=3.57, S D=2.30)$ and there were no gender differences in elasticity and breakpoint. For the risk/protective factors included, women had a higher score on the protective behaviors measure $(M=53.95, S D=12.02, t(204)=-2.99, p<.01)$ than male drinkers $(M=48.76, S D=12.88)$, whereas men had higher sensation seeking scores $(M=14.96, S D=3.03, t(205)=2.55, p=.01)$ than women $(M=13.88, S D=3.03)$. There were no significant gender differences in depression scores. 


\section{Associations among BE Measures of Alcohol Value, Alcohol Measures, and Other Risk Factors}

Table 2 presents the results of the bivariate correlation analyses between each of the $\mathrm{BE}$ measures of alcohol value, typical weekly drinking, total problems, protective behaviors, sensation-seeking, and depressive symptoms.

\section{Factor Structure of BE Measures of Alcohol Value}

The chi-square value for the Amplitude factor was not statistically significant, indicating excellent fit: $\chi^{2}(2, N=207)=4.90, p=.09$. Standardized factor loadings for $\mathrm{O}_{\max }$, intensity, $\mathrm{RR}$, and RDEA were $.81, .71, .46$, and .51 , respectively (all $p s<.001$ ). The overall model fit of the Persistence factor was not as strong as the Amplitude factor. The chi-square value was statistically significant, $\chi^{2}(2, N=207)=43.19, p<.001$, although other fit indices indicated adequate fit (e.g., $\mathrm{CFI}=.90, \mathrm{IFI}=.91)$. Standardized factor loadings for $\mathrm{O}_{\max }, \mathrm{P}_{\max }$, breakpoint, and elasticity were $.96, .58, .65$, and -.86 , respectively $(p<.001)$.

\section{Predictive Utility of BE measures of Alcohol Value}

Table 3 presents the regression outcomes. Intensity, breakpoint, $\mathrm{O}_{\max }$, elasticity, $R R$, and RDEA were all statistically significant predictors of typical weekly drinking $\left(\Delta \mathrm{R}^{2}\right.$ range $=$. 03-.17) in models that controlled for gender, age, and ethnicity (White versus non-White). Both Amplitude $\left(\Delta \mathrm{R}^{2}=.22\right)$ and Persistence $\left(\Delta \mathrm{R}^{2}=.02\right)$ composite scores were also significant predictors. In regression models that controlled for gender, age, ethnicity, and weekly alcohol consumption, breakpoint, $\mathrm{O}_{\max }, \mathrm{P}_{\max }$, elasticity, and RR significantly predicted total problems $\left(\Delta \mathrm{R}^{2}\right.$ range $\left.=.02-.06\right)$. The Amplitude $\left(\Delta \mathrm{R}^{2}=.02\right)$ and Persistence $\left(\Delta \mathrm{R}^{2}=.04\right)$ composite scores significantly predicted problems as well.

For men, intensity, $\mathrm{O}_{\max }$, elasticity, RR, RDEA, and Amplitude were significant predictors of typical drinking. For women, intensity, breakpoint, $\mathrm{O}_{\max }$, elasticity, RR, RDEA, Amplitude, and Persistence were significant predictors. For the replication of the problem regressions, $\mathrm{O}_{\max }$, elasticity, and Persistence significantly predicted total problems for men. For women, $\mathrm{P}_{\max }, \mathrm{RR}$, and Persistence were significant predictors (for statistics of these results, please refer to supplemental material available online).

For typical weekly drinking, when intensity, breakpoint and $\mathrm{O}_{\max }$ were included in the second step of the regression, intensity and $\mathrm{O}_{\max }$ remained statistically significant predictors. When elasticity, RR, and RDEA were included, elasticity and RR remained significant predictors of typical weekly drinking. For alcohol-related problems, when breakpoint, $\mathrm{O}_{\max }, \mathrm{P}_{\max }$, elasticity, and $\mathrm{RR}$ were entered into the second step of the regression, $\mathrm{O}_{\max }$ and $\mathrm{RR}$ continued to be significant predictors.

For men, when intensity and $\mathrm{O}_{\max }$ were entered in the second step of the regression, both remained significant predictors of weekly drinking. When elasticity, RR, and RDEA were entered together, elasticity and RR remained significant. For men, when $\mathrm{O}_{\max }$ and elasticity were entered into a single step, only $\mathrm{O}_{\max }$ remained a significant predictor of total problems. For women, when intensity, breakpoint, and $\mathrm{O}_{\max }$, were entered into a single step to predict typical weekly drinking, intensity and $\mathrm{O}_{\max }$ remained significant. When elasticity, $\mathrm{RR}$, and 
RDEA were entered into step two, only RR remained significant. For problems, when $\mathrm{P}_{\max }$ and RR were entered together, only RR remained significant for women.

Table 4 presents the results of the competitive regression analyses. Protective behaviors significantly predicted total problems, and when protective behaviors were controlled for $\mathrm{O}_{\max }, \mathrm{P}_{\max }, \mathrm{RR}$, and the Amplitude and Persistence composites continued to be statistically significant predictors. Sensation-seeking was not a statistically significant predictor of total alcohol-related problems. Finally, depression was a statistically significant predictor of total problems. When depression was controlled for, breakpoint, $\mathrm{O}_{\max }, \mathrm{P}_{\max }$, elasticity, RR, and the Persistence composite continued to account for statistically significant variance in alcohol-related consequences.

Protective behaviors were a significant predictor for both men and women. For men, $\mathrm{O}_{\max }$ and Persistence continued to be significant predictors of problems when controlling for protective behaviors; for women, $\mathrm{P}_{\max }$ and $\mathrm{RR}$ remained significant. Consistent with the total sample analyses, sensation-seeking was not a predictor of problems for men or women. Depression was a significant predictor of problems for both genders. For men, intensity, $\mathrm{O}_{\max }$, and Persistence remained significant when controlling for depression. Of note, the relationship between intensity and problems was negative. For women, $\mathrm{O}_{\max }$, elasticity, $\mathrm{RR}$, and Persistence remained significant when controlling for depression.

\section{Discussion}

Behavioral economic (BE) models of addiction emphasize that relative levels of resource allocation toward alcohol reflect an important component of motivation for drinking that is not captured by standard measures of alcohol consumption or problems. There are a variety of $\mathrm{BE}$ indices of alcohol reward value, and our results suggest that these $\mathrm{BE}$ measures form a heterogeneous construct comprised of two primary factors. The seven metrics demonstrated differential relations with each other as well as with alcohol use and related problems, suggesting that these conceptually related metrics provide unique information concerning alcohol problem severity. Some of the BE measures also demonstrated predictive utility beyond well-established predictors.

Our findings suggest that these variables are measuring distinct facets of drug-related reinforcement that are involved in a range of addictive behaviors (MacKillop \& Murphy, 2007; MacKillop et al., 2008; Murphy, MacKillop, Tidey, Brazil, \& Colby, 2011). The results of our confirmatory factor analysis suggest that there are two underlying factors involved in alcohol valuation. One factor, the Amplitude factor (intensity, $\mathrm{O}_{\max }, \mathrm{RR}$, and RDEA), could be conceptualized as the amount of alcohol consumed, and also the centrality and "space" that alcohol and alcohol-related behaviors occupy in a person's behavioral repertoire. The other factor, a replication of the Persistence factor put forth by MacKillop and colleagues (2009), includes breakpoint, $\mathrm{P}_{\max }$, elasticity, and $\mathrm{O}_{\max }$ and provides information about price sensitivity. Similar to MacKillop and colleagues (2009) results we found that $\mathrm{O}_{\max }$ loaded on both factors demonstrating that it provides information about the financial resources an individual allocates toward alcohol as well as their level of price sensitivity.

Exp Clin Psychopharmacol. Author manuscript; available in PMC 2015 June 01. 
All of the Amplitude indices were significantly correlated with typical weekly drinking and these measures were the most robust predictors of alcohol use even when controlling for demographic variables and when multiple significant predictors were entered into the regression models. Among heavy drinkers, intensity, $\mathrm{O}_{\max }, \mathrm{RR}$, demonstrated moderate to large effect sizes with typical drinks when controlling for demographics $(r s=.41, .37$, and . 32 , respectively) and likely can provide unique information about drinking patterns which may in turn identify those students at risk for immediate consequences related to heavy alcohol use.

Breakpoint, $\mathrm{O}_{\max }, \mathrm{P}_{\max }$, elasticity, and RR were supported as unique predictors of alcohol problems even after controlling for drinking level and demographic variables associated with alcohol use ( $r \mathrm{~s}=.14, .24, .17, .17$, and .17 , respectively). These findings were largely supported when controlling for other well-established predictors of alcohol problems (protective behavioral strategies, depression), suggesting that these BE variables reflect a unique element of alcohol severity (insensitivity to price, elevated relative behavioral/ monetary resource allocation towards alcohol) that is partially independent of typical drinking and variability in mood and protective behavioral strategies. This extends a previous study that indicated that symptoms of depression (and PTSD) were associated with elevated demand by suggesting that depression does not account for the relation between elevated demand and alcohol problems (Murphy et al., 2013). Insensitivity to price, or in the case of RR insensitivity to alternative substance-free activity reinforcers, may override contextual features or potential risks that might otherwise limit drinking (Gentile et al., 2012; Skidmore \& Murphy, 2010). Although intensity was positively correlated with alcohol-related problems, contrary to our hypotheses, it was not a significant predictor of problems when demographic variables and alcohol use were controlled for. This may be a statistical artifact due to the fact that intensity is largely co-linear with weekly drinking level, which is a robust predictor of problems.

The predictive utility of the factor composites were similar to our findings for the individual BE measures in that Amplitude and Persistence demonstrated differential predictive utility. Both composites were statistically significant predictors of alcohol use and related problems; however, Amplitude demonstrated a larger effect size with drinking than with problems $(r \mathrm{~s}$ $=.47, .14$ respectively), whereas the opposite pattern was true of Persistence $(r \mathrm{~s}=.14, .20$ for drinking and problems, respectively). The Persistence factor also demonstrated greater utility for predicting problems as it continued to account for variance in problems above protective behaviors and depression. These results further support the use of the Persistence metrics as especially useful indicators of risk for consequences among heavy drinkers. The Persistence composite may be especially useful given that two of the indices $\left(\mathrm{P}_{\max }\right.$, elasticity) have only moderate test-retest reliability (Murphy et al., 2009) and the use of a composite often increases reliability. Additionally, the inclusion of elasticity, a measure of essential value that performed well in many of our regressions ( $r$ range $=.10-.36$ ), may lend to the strength of the Persistence measure as a problem severity indicator.

This is the first study to evaluate RR in the context of other predictors and the results support its predictive validity above and beyond alcohol use, other alcohol valuation metrics, and other predictors for alcohol-related problems. The inclusion of items that assess 
actual behavior (reports of past month engagement and enjoyment related to alcohol-related and alcohol-free activities) is an advantage and may explain some of the utility of RR. Previous research suggests that chronic substance abusers demonstrate less sensitivity (i.e., dampened pleasure and cortical activation) in response to drug-free rewards (Parvaz et al., 2012; Volkow et al., 2010), and RR may provide an early index of this key process of addiction. In comparison with all of the metrics included in our study, only RR includes a specific "enjoyment" component that may allow for more sensitivity in the measurement of reinforcement and thus make it a more effective problem severity indicator. Individuals for whom alcohol provides the most reliable source of enjoyment may be less able to modify their drinking in order to avoid untoward outcomes and may experience greater levels of problems (Volkow et al., 2010). Future longitudinal research that includes independent reward sensitivity indices (for both alcohol-related and alcohol-free stimuli) is necessary to clarify the process by which the relative overvaluation of alcohol occurs and to determine the extent to which RR reflects both overvaluation of alcohol rewards and undervaluation of alcohol-free rewards. RR could reflect both an underlying genetically influenced affinity for alcohol-related rewards as well as diminished responsiveness to substance-free rewards due to chronic substance use and/or exposure to environments that do not provide reliable access to substance-free rewards (Carroll, Anker, \& Perry, 2009; Vuchinich\& Heather, 2003).

Our results related to RDEA and alcohol use were consistent with previous research indicating that monetary ratios predict changes in alcohol use (Tucker et al., 2002, 2006, 2008, 2009, 2012). RDEA did not contribute to unique variance in alcohol-related problems when controlling for age, ethnicity, gender, and drinking. Thus, it may be that RDEA provides unique insight into drinking behaviors but not consequences related to drinking. Due to the general absence of monetary savings among college students, the RDEA does not reflect relative valuation of immediate compared to delayed rewards, also known as delayed reward discounting, unlike the ASDE. Greater levels of delayed reward discounting are associated with increased severity of addictive disorders (MacKillop et al., 2011) and alcohol demand (MacKillop et al., 2010) suggesting that delayed reward discounting provides unique information about an individual's risk and problem severity. Thus, the RDEA may be a less useful indicator of alcohol-reward value and problem severity than the ASDE.

Many of the results for the total sample were replicated across genders; however, some gender differences did emerge. For alcohol use, there were very few gender differences suggesting that the $\mathrm{BE}$ measures of alcohol reward value provide unique information about drinking patterns for both men and women. There were a few gender differences in the association between the alcohol reward measures and alcohol-related problems. For men, it appears that $\mathrm{O}_{\max }(r$ range $=.24-.28)$ and the Persistence composite $(r$ range $=.17-.20)$ may be the most robust predictors of problems, as these variables continued to account for variance above established risk factors. For women, RR ( $r$ range $=.22-.24$ ) may be the most useful predictor of alcohol-related problems.

This study had a number of strengths including multiple alcohol reward value predictors and a relatively large and diverse sample of heavy drinking college students. Nevertheless, the findings of this study should be interpreted in light of some limitations. First, all measures 
included were self-reports. Although previous research has found that the self-report BE indices are valid and highly correlated with actual behavior (Amlung et al., 2011; Jacobs \& Bickel, 1999) future research should examine laboratory measures of alcohol reward value. Second, this study was cross-sectional and future studies should examine the relations among alcohol valuation and problems longitudinally to determine the causal relation between alcohol valuation and use. Behavioral economic models suggest a recursive longitudinal relation between increasing substance use and increasing reward value (Bickel et al., 2014; Rachlin, 1997).

Additional future research directions include assessing the associations between the various metrics and other mechanisms that underlie alcohol problem severity (e.g., cognitive control, implicit associations, negative reinforcement, impulsivity). The strength of RR and the Amplitude and Persistence composites in our analyses suggest that these variables will lend themselves well to future investigations that seek to replicate and extend our findings that $\mathrm{BE}$ measures provide unique information about alcohol problem severity. Researchers should also seek to extend this work by further addressing how alcohol valuation changes over time and following an intervention. For example, future research using the Alcohol Purchase Task should assess how demand for alcohol changes longitudinally and following treatment and how the change in demand is related to hypothesized mechanisms of change (e.g., motivation to change) and outcomes. Similar to previous research that found that RR decreased when drinking decreased following an intervention (Murphy et al., 2005), alcohol demand may decrease in response to treatment. Finally, future studies should investigate the associations between discounting and demand (Bickel et al., 2014).

The results of this study present interesting and important clinical implications as well. First, the different strengths of associations between the BE metrics and alcohol use/problems suggest that some alcohol valuation metrics may be especially useful screening and outcome measures in clinical contexts. Intensity and $\mathrm{O}_{\max }$ could be especially useful clinical screening measures for risky alcohol use as they can be measured with the very brief Alcohol Purchase Task (intensity with a single item). Although our study did not find that intensity predicted problems, previous research has found intensity to be associated with problem severity suggesting that it could be a brief and convenient empirically-supported screening method. RR may also have specific clinical utility with treatment planning and intervention. It could be used to indicate the need for a treatment that increases substancefree activities (Murphy et al., 2012) or reduced delayed reward discounting (Bickel, Yi, Landes, Hill, \& Baxter, 2011), or delivered as feedback, such that individuals receiving interventions could be provided information about RR, or changes in RR over time, in order to increase or maintain their motivation to change their alcohol use. RR may also provide a useful outcome measure, for example, decreases in RR would suggest that an individual is allocating less of their behavior or deriving less of their enjoyment from alcohol-related activities, which are important goals for efficacious and effective substance use treatments (Petry, 2012) and are not captured by existing measures. The converse could also be true, increases in RR, even in the absence of changes in drinking, might be a poor prognostic sign that indicates a need for more intense treatment or provide empirical evidence that a specific treatment is not efficacious (Borsari, Tevyaw, Barnett, Kahler, \& Monti, 2007).

Exp Clin Psychopharmacol. Author manuscript; available in PMC 2015 June 01. 
The results of the present study further support the conceptualization of reinforcement from alcohol as a heterogeneous construct and more generally support the utility of a BE framework for the study and understanding of alcohol use. Our results suggest that the metrics associated with the Persistence or price sensitivity factor and RR appear to demonstrate the most consistent and strongest relations with alcohol-related problems. These indices, when used in conjunction with other risk factors such as elevated consumption and mood difficulties may provide a comprehensive model of substance use severity in emerging adult populations that may ultimately prove useful in identifying those young adults who are most at risk for escalating severity and in need of intervention services.

\section{Supplementary Material}

Refer to Web version on PubMed Central for supplementary material.

\section{Acknowledgments}

This research was supported by a grant from the Alcohol Research Foundation (ABMRF) awarded to James G. Murphy, Ph.D., and an NIAAA T32 training grant (5T32AA013525-08) to Jessica R. Skidmore, Ph.D.

\section{References}

Amlung MT, Acker J, Stojek MK, Murphy JG, MacKillop J. Is talk "cheap”? An initial investigation of the equivalence of Alcohol Purchase Task performance for hypothetical and actual rewards. Alcoholism: Clinical \& Experimental Research. 2011; 36(4):716-724.

Bickel, WK.; Jarmolowicz, DP.; MacKillop, J.; Epstein, LH.; Carr, K.; Mueller, E.; Waltz, TJ. The behavioral economics of reinforcement pathologies: Novel approaches to addictive disorders. In: Shaffer, H.; LaPlante, DA.; Nelson, SE., editors. APA addiction syndrome handbook, vol. 2: Recovery, prevention, and other issues. Washington, DC US: American Psychological Association; 2012. p. 333-363.

Bickel W, Johnson M, Koffarnus M, MacKillop J, Murphy JG. The behavioral economics of substance use disorders: Reinforcement pathologies and their repair. Annual Review of Clinical Psychology. 2014; 10:20.1-20.37.10.1146/annurev-clinpsy-032813-153724

Bickel WK, Marsch LA, Carroll ME. Deconstructing relative reinforcing efficacy and situating the measures of pharmacological reinforcement with behavioral economics: A theoretical proposal. Psychopharmacology. 2000; 153(1):44-56.10.1007/s002130000589 [PubMed: 11255928]

Bickel WK, Yi R, Landes RD, Hill PF, Baxter C. Remember the future: Working memory training decreases delay discounting among stimulant addicts. Biological Psychiatry. 2011; 69(3):260 265.10.1016/j.biopsych.2010.08.017 [PubMed: 20965498]

Bidwell L, MacKillop J, Murphy JG, Tidey JW, Colby SM. Latent factor structure of a behavioral economic cigarette demand curve in adolescent smokers. Addictive Behaviors. 2012; 37(11):12571263.10.1016/j.addbeh.2012.06.009 [PubMed: 22727784]

Borsari B, Tevyaw T, Barnett NP, Kahler CW, Monti PM. Stepped care for mandated college students: A pilot study. The American Journal On Addictions. 2007; 16(2):131137.10.1080/10550490601184498 [PubMed: 17453615]

Bruner NR, Johnson MW. Demand curves for hypothetical cocaine in cocaine-dependent individuals. Psychopharmacology. 201310.1007/s00213-013-3312-5

Buscemi J, Murphy JG, Martens MP, McDevitt-Murphy ME, Dennhardt AA, Skidmore JR. Helpseeking for alcohol-related problems in college students: Correlates and preferred resources. Psychology Of Addictive Behaviors. 2010; 24(4):571-580.10.1037/a0021122 [PubMed: 21198220]

Carroll ME, Anker JJ, Perry JL. Modeling risk factors for nicotine and other drug abuse in the preclinical laboratory. Drug and Alcohol Dependence. 2009; 104:S1 70-78.10.1016/j.drugalcdep. 2008.11.011 
Collins R, Parks G, Marlatt G. Social determinants of alcohol consumption: The effects of social interaction and model status on the self-administration of alcohol. Journal of Consulting and Clinical Psychology. 1985; 53:189-200.10.1037/0022-006X.53.2.189 [PubMed: 3998247]

Correia C, Carey K. Applying behavioral theories of choice to substance use in a sample of psychiatric outpatients. Psychology of Addictive Behaviors. 1999; 13:207-212.10.1037/0893-164X.13.3.207

Correia C, Carey K, Simons J, Borsari B. Relationships between binge drinking and substance-free reinforcement in a sample of college students: A preliminary investigation. Addictive Behaviors. 2003; 28:361-368.10.1016/S0306-4603(01)00229-5 [PubMed: 12573686]

Correia C, Simons J, Carey K, Borsari B. Predicting drug use: Application of behavioral theories of choice. Addictive Behaviors. 1998; 23:705-710.10.1016/S0306-4603(98)00027-6 [PubMed: 9768306]

Dennhardt AA, Murphy JG. Associations between depression, distress tolerance, delay discounting, and alcohol-related problems in European American and African American college students. Psychology Of Addictive Behaviors. 2011; 25(4):595-604.10.1037/a0025807 [PubMed: 21988480]

Gentile ND, Librizzi EH, Martinetti MP. Academic constraints on alcohol consumption in college students: A behavioral economic analysis. Experimental and Clinical Psychopharmacology. 2012; 20:390. [PubMed: 22889038]

Ham L, Hope D. College students and problematic drinking: A review of the literature. Clinical Psychology Review. 2003; 23:719-759.10.1016/S0272-7358(03)00071-0 [PubMed: 12971907]

Heinz AJ, Lilje TC, Kassel JD, de Wit H. Quantifying Reinforcement Value and Demand for Psychoactive Substances in Humans. Current drug abuse reviews. 2012; 5:257. [PubMed: 23062106]

Herrnstein R. On the law of effect. Journal of the Experimental Analysis of Behavior. 1970; 13:243266.10.1901/jeab.1970.13-243 [PubMed: 16811440]

Hingson RW, Zha W, Weitzman ER. Magnitude of and trends in alcohol-related mortality and morbidity among U.S. college students ages 18-24, 1998-2005. Journal of Studies on Alcohol and Drugs. 2009; (Supp 16):12-20. [PubMed: 19538908]

Hoyle R, Stephenson M, Palmgreen P, Pugzles Lorch E, Donohew R. Reliability and validity of a brief measure of sensation-seeking. Personality and Individual Differences. 2002; 32:401-414.10.1016/ S0191-8869(01)00032-0

Hursh SR, Silberberg A. Economic demand and essential value. Psychological Review. 2008; 115(1): 186-198.10.1037/0033-295X.115.1.186 [PubMed: 18211190]

Jackson K, Sher K, Gotham H, Wood P. Transitioning into and out of large-effect drinking in young adulthood. Journal of Abnormal Psychology. 2001; 110:378-391.10.1037/0021-843X.110.3.378 [PubMed: 11502081]

Jacobs E, Bickel W. Modeling drug consumption in the clinic using simulation procedures: Demand for heroin and cigarettes in opioid-dependent outpatients. Experimental and Clinical Psychopharmacology. 1999; 7:412-426.10.1037/1064-1297.7.4.412 [PubMed: 10609976]

Kiselica AM, Borders A. The reinforcing efficacy of alcohol mediates associations between impulsivity and negative drinking outcomes. Journal of Studies on Alcohol and Drugs. 2013; 74(3):490. [PubMed: 23490580]

Kivlahan D, Marlatt G, Fromme K, Coppel D, Williams E. Secondary prevention with college drinkers: Evaluation of an alcohol skills training program. Journal of Consulting and Clinical Psychology. 1990; 58:805-810.10.1037/0022-006X.58.6.805 [PubMed: 2292630]

Lejuez CW, Magidson JF, Mitchell SH, Sinha R, Stevens MC, De Wit H. Behavioral and biological indicators of impulsivity in the development of alcohol use, problems, and disorders. Alcoholism: Clinical And Experimental Research. 2010; 34(8):1334-1345.

MacKillop J, Amlung MT, Few LR, Ray LA, Sweet LH, Munafò MR. Delayed reward discounting and addictive behavior: a meta-analysis. Psychopharmacology. 2011; 216:305-321. [PubMed: 21373791]

MacKillop J, Miranda R, Monti P, Ray L, Murphy J, Rohsenow D, Gwaltney CJ. Alcohol demand, delayed reward discounting, and craving in relation to drinking and alcohol use disorders. Journal of Abnormal Psychology. 2010; 119:106-114.10.1037/a0017513 [PubMed: 20141247] 
Mackillop J, Murphy J. A behavioral economic measure of demand for alcohol predicts brief intervention outcomes. Drug and Alcohol Dependence. 2007; 89:227-233.10.1016/j.drugalcdep. 2007.01.002 [PubMed: 17289297]

MacKillop J, Murphy J, Ray L, Eisenberg D, Lisman S, Lum J, David S. Further validation of a cigarette purchase task for assessing the relative reinforcing efficacy of nicotine in college smokers. Experimental and Clinical Psychopharmacology. 2008; 16:5765.10.1037/1064-1297.16.1.57 [PubMed: 18266552]

MacKillop J, Murphy J, Tidey J, Kahler C, Ray L, Bickel W. Latent structure of facets of alcohol reinforcement from a behavioral economic demand curve. Psychopharmacology. 2009; 203:3340.10.1007/s00213-008-1367-5 [PubMed: 18925387]

MacKillop J, O’Hagen S, Lisman S, Murphy JG, Ray LA, Tidey JW, Monti PM. Behavioral economic analysis of cue elicited craving for alcohol. Addiction. 2010; 105(9):1599-1607.10.1111/j. 1360-0443.2010.03004.x [PubMed: 20626376]

MacPhillamy D, Lewinsohn P. The pleasant events schedule: Studies on reliability, validity, and scale intercorrelation. Journal of Consulting and Clinical Psychology. 1982; 50:363380.10.1037/0022-006X.50.3.363

Martens MP, Ferrier AG, Sheehy MJ, Corbett K, Anderson DA, Simmons A. Development of the Protective Behavioral Strategies Survey. Journal of Studies on Alcohol. 2005; 66:698-705. [PubMed: 16329461]

Martens MP, Martin JL, Littlefield AK, Murphy JG, Cimini MD. Changes in protective behavioral strategies and alcohol use among college students: A prospective analysis. Drug and Alcohol Dependence. 2011; 118:504-507. [PubMed: 21612879]

Murphy J, Correia C, Colby S, Vuchinich R. Using Behavioral Theories of Choice to Predict Drinking Outcomes Following a Brief Intervention. Experimental and Clinical Psychopharmacology. 2005; 13:93-101.10.1037/1064-1297.13.2.93 [PubMed: 15943542]

Murphy JG, Dennhardt AA, Skidmore JR, Borsari B, Barnett NP, Colby SM, Martens MP. A randomized controlled trial of a behavioral economic supplement to brief motivational interventions for college drinking. Journal of Consulting and Clinical Psychology. 201210.1037/ a0028763

Murphy JG, Dennhardt AA, Skidmore JR, Martens MP, McDevitt-Murphy ME. Computerized versus motivational interviewing alcohol interventions: Impact on discrepancy, motivation, and drinking. Psychology Of Addictive Behaviors. 2010; 24(4):628-639.10.1037/a0021347 [PubMed: 21198224]

Murphy J, MacKillop J. Relative reinforcing efficacy of alcohol among college student drinkers. Experimental and Clinical Psychopharmacology. 2006; 14:219-227.10.1037/1064-1297.14.2.219 [PubMed: 16756426]

Murphy J, MacKillop J, Skidmore J, Pederson A. Reliability and validity of a demand curve measure of alcohol reinforcement. Experimental and Clinical Psychopharmacology. 2009; 17:396404.10.1037/a0017684 [PubMed: 19968404]

Murphy JG, MacKillop J, Tidey JW, Brazil LA, Colby SM. Validity of a Demand Curve Measure of Nicotine Reinforcement with Adolescent Smokers. Drug and Alcohol Dependence. 2011; 113(23):207-214.10.1016/j.drugalcdep.2010.08.004 [PubMed: 20832200]

Murphy JG, Yurasek AM, Dennhardt AA, Skidmore JR, McDevitt-Murphy ME, MacKillop J, Martens MP. Symptoms of depression and PTSD are associated with elevated alcohol demand. Drug and Alcohol Dependence. 2013; 127:129-136.10.1016/j.drugalcdep.2012.06.022 [PubMed: 22809894]

National Institute on Alcohol Abuse and Alcoholism. College Drinking. 2012. Retrieved from http:// pubs.niaaa.nih.gov/publications/CollegeFactSheet/CollegeFactSheet.pdf

O'Donnell K, Wardle J, Dantzer C, Steptoe A. Alcohol consumption and symptoms of depression in young adults from 20 countries. Journal of Studies on Alcohol. 2006; 67:837-840. [PubMed: 17061000]

O'Neill S, Sher K. Physiological alcohol dependence symptoms in early adulthood: A longitudinal perspective. Experimental and Clinical Psychopharmacology. 2000; 8:493508.10.1037/1064-1297.8.4.493 [PubMed: 11127421] 
Parvaz MA, Maloney T, Moeller SJ, Woicik PA, Alia-Klein N, Telang F, Goldstein RZ. Sensitivity to monetary reward is most severely compromised in recently abstaining cocaine addicted individuals: A cross-sectional ERP study. Psychiatry Research: Neuroimaging. 201210.1016/ j.pscychresns.2012.01.001

Paschall M, Freisthler B, Lipton R. Moderate alcohol use and depression in young adults: Findings from a national longitudinal study. American Journal of Public Health. 2005; 95:453-457.10.2105/ AJPH.2003.030700 [PubMed: 15727976]

Pearson MR. Use of alcohol protective behavioral strategies among college students: A critical review. Clinical Psychology Review. 2013; 33(8):1025-1040. http://dx.doi.org/10.1016/j.cpr.2013.08.006. [PubMed: 24036089]

Petry, NM. Contingency management for substance abuse treatment: A guide to implementing evidence-based practice. New York, NY US: Routledge/Taylor \& Francis Group; 2012.

Rachlin H. Four teleological theories of addiction. Psychonomic Bulletin \& Review. 1997; 4:462-473.

Radloff L. The use of the Center for Epidemiologic Studies Depression Scale in adolescents and young adults. Journal of Youth and Adolescence. 1991; 20:149-166.10.1007/BF01537606 [PubMed: 24265004]

Read J, Kahler C, Strong D, Colder C. Development and Preliminary Validation of the Young Adult Alcohol Consequences Questionnaire. Journal of Studies on Alcohol. 2006; 67:169-177. [PubMed: 16536141]

Read J, Merrill J, Kahler C, Strong D. Predicting functional outcomes among college drinkers: Reliability and predictive validity of the Young Adult Alcohol Consequences Questionnaire. Addictive Behaviors. 2007; 32:2597-2610.10.1016/j.addbeh.2007.06.021 [PubMed: 17706888]

Shean G, Baldwin G. Sensitivity and specificity of depression questionnaires in a college-age sample. Journal of Genetic Psychology. 2008; 169:281-288.10.3200/GNTP.169.3.281-292 [PubMed: 18788328]

Skidmore JR, Murphy JG. The Effect of Drink Price and Next-Day Responsibilities on College Student Drinking: A Behavioral Economic Analysis. Psychology of Addictive Behaviors. 201010.1037/a0021118

Slutske WS. Alcohol use disorders among US college students and their non-college-attending peers. Archives Of General Psychiatry. 2005; 62(3):321-327.10.1001/archpsyc.62.3.321 [PubMed: 15753245]

Smith AE, Martens MP, Murphy JG, Buscemi J, Yurasek AM, Skidmore JR. Reinforcing efficacy moderates the relationship between impulsivity-related traits and alcohol use. Experimental and Clinical Psychopharmacology. 2010; 18(6):521-529.10.1037/a0021585 [PubMed: 21186926]

Stanger C, Budney AJ, Bickel WK. A developmental perspective on neuroeconomic mechanisms of contingency management. Psychology Of Addictive Behaviors. 201210.1037/a0028748

Stephenson M, Hoyle R, Palmgreen P, Slater M. Brief measures of sensation seeking for screening and large-scale surveys. Drug and Alcohol Dependence. 2003; 72:279-286.10.1016/j.drugalcdep. 2003.08.003 [PubMed: 14643945]

Tabachnick, BG.; Fidell, LS. Using Multivariate Analysis. Boston, MA, US: Allyn and Bacon; 2001.

Tucker J, Foushee H, Black B. Behavioral economic analysis of natural resolution of drinking problems using IVR self-monitoring. Experimental and Clinical Psychopharmacology. 2008; 16:332-340.10.1037/a0012834 [PubMed: 18729688]

Tucker JA, Roth DL, Huang J, Crawford M, Simpson CA. Effects of interactive voice response selfmonitoring on natural resolution of drinking problems: Utilization and behavioral economic factors. Journal Of Studies On Alcohol And Drugs. 2012; 73(4):686-698. [PubMed: 22630807]

Tucker J, Roth D, Vignolo M, Westfall A. A behavioral economic reward index predicts drinking resolutions: Moderation revisited and compared with other outcomes. Journal of Consulting and Clinical Psychology. 2009; 77:219-228.10.1037/a0014968 [PubMed: 19309182]

Tucker J, Vuchinich R, Black B, Rippens P. Significance of a behavioral economic index of reward value in predicting drinking problem resolution. Journal of Consulting and Clinical Psychology. 2006; 74:317-326.10.1037/0022-006X.74.2.317 [PubMed: 16649876] 
Tucker J, Vuchinich R, Rippens P. Predicting natural resolution of alcohol-related problems: A prospective behavioral economic analysis. Experimental and Clinical Psychopharmacology. 2002; 10:248-257.10.1037/1064-1297.10.3.248 [PubMed: 12233985]

Vik P, Carrello P, Tate S, Field C. Progression of consequences among heavy-drinking college students. Psychology of Addictive Behaviors. 2000; 14:91-101.10.1037/0893-164X.14.2.91 [PubMed: 10860108]

Volkow ND, Fowler JS, Wang G, Telang F, Logan J, Jayne M, Swanson JM. Cognitive control of drug craving inhibits brain reward regions in cocaine abusers. Neuroimage. 2010; 49(3):25362543.10.1016/j.neuroimage.2009.10.088 [PubMed: 19913102]

Vuchinich, RE.; Heather, N. Choice, behavioural economics and addiction. Amsterdam Netherlands: Pergamon/Elsevier Science Inc; 2003.

Wechsler H, Lee J, Nelson T, Lee H. Drinking levels, alcohol problems and secondhand effects in substance-free college residences: Results of a national study. Journal of Studies on Alcohol. 2001; 62:23-31. [PubMed: 11271961]

Yurasek AM, Murphy JG, Dennhardt AA, Skidmore JR, Buscemi J, McCausland C, Martens MP. Drinking motives mediate the relationship between reinforcing efficacy and alcohol consumption and problems. Journal of Studies on Alcohol and Drugs. 2011; 73(6):991-999. [PubMed: 22051213] 


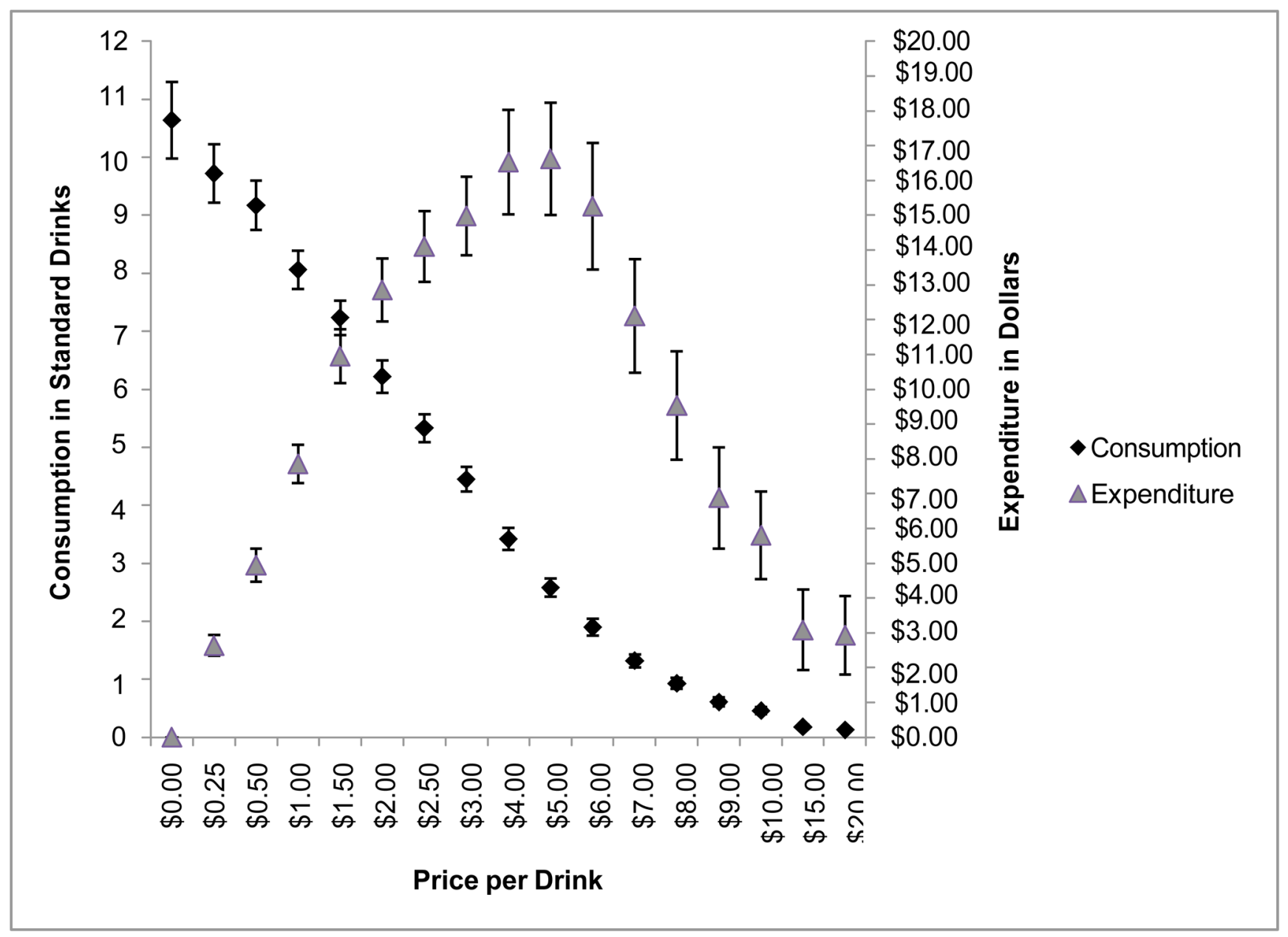

Figure 1.

Demand and expenditure curves. Means and SEs for hypothetical alcohol consumption (left axis) and expenditures (right axis) at 17 levels of price. Consumption is represented with diamonds and expenditures are represented with triangles. 


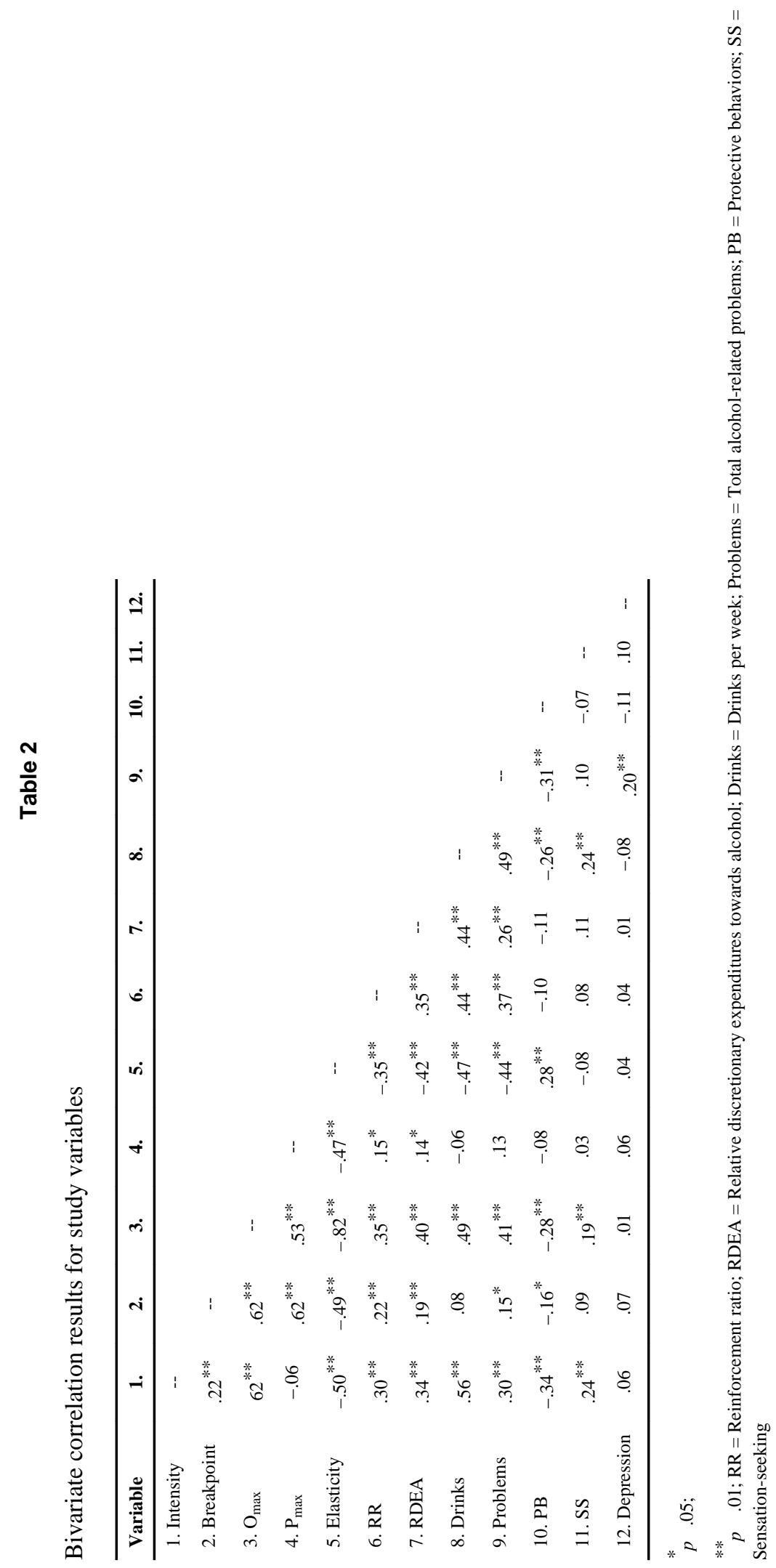

Exp Clin Psychopharmacol. Author manuscript; available in PMC 2015 June 01. 


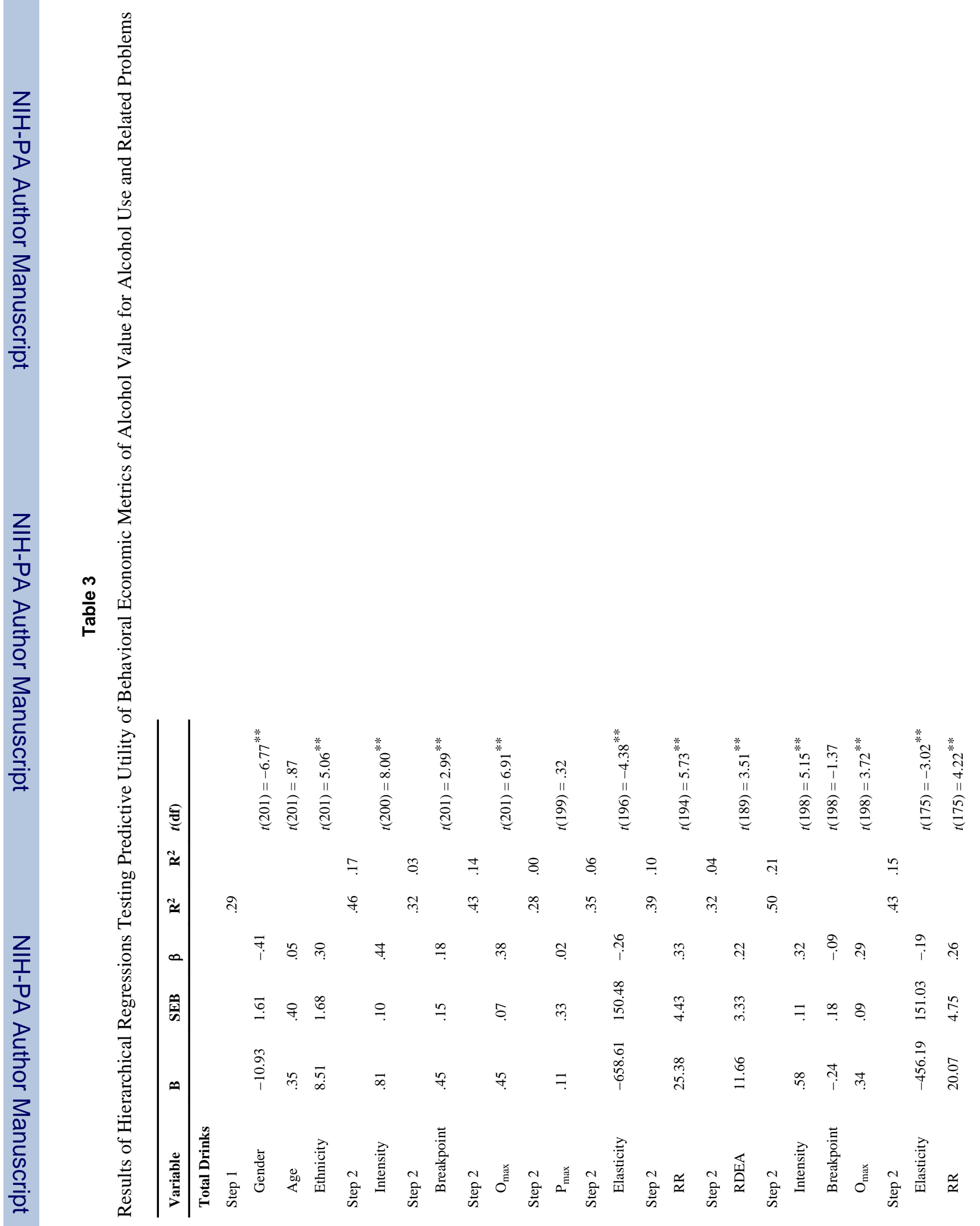




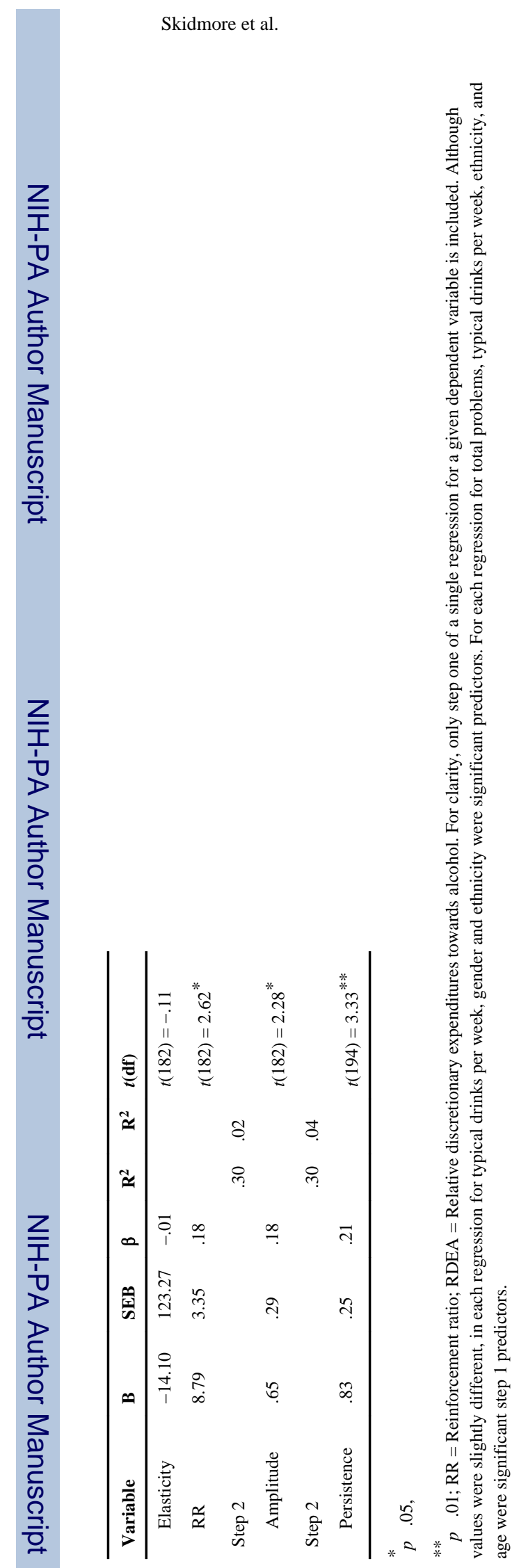

Exp Clin Psychopharmacol. Author manuscript; available in PMC 2015 June 01. 


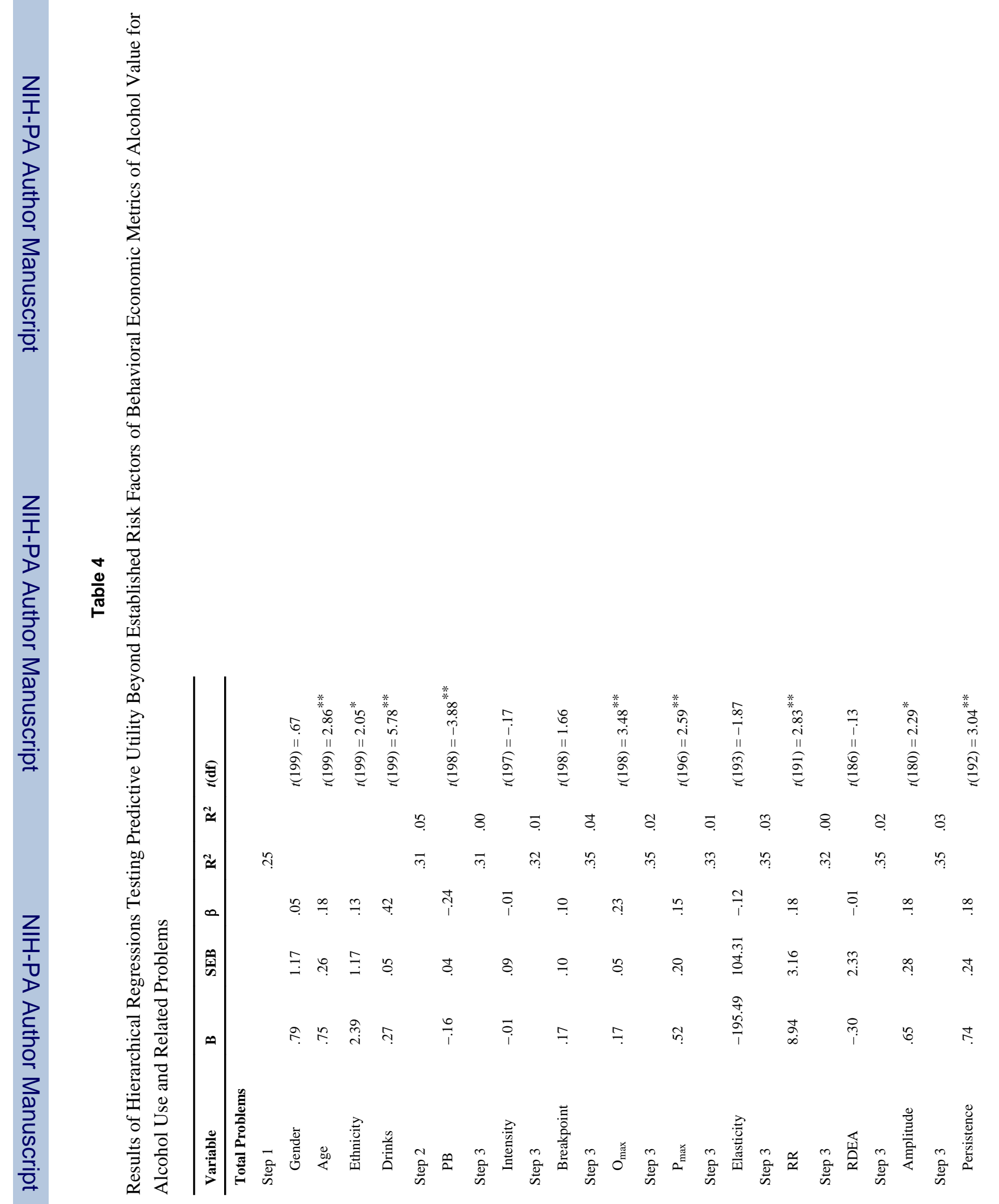




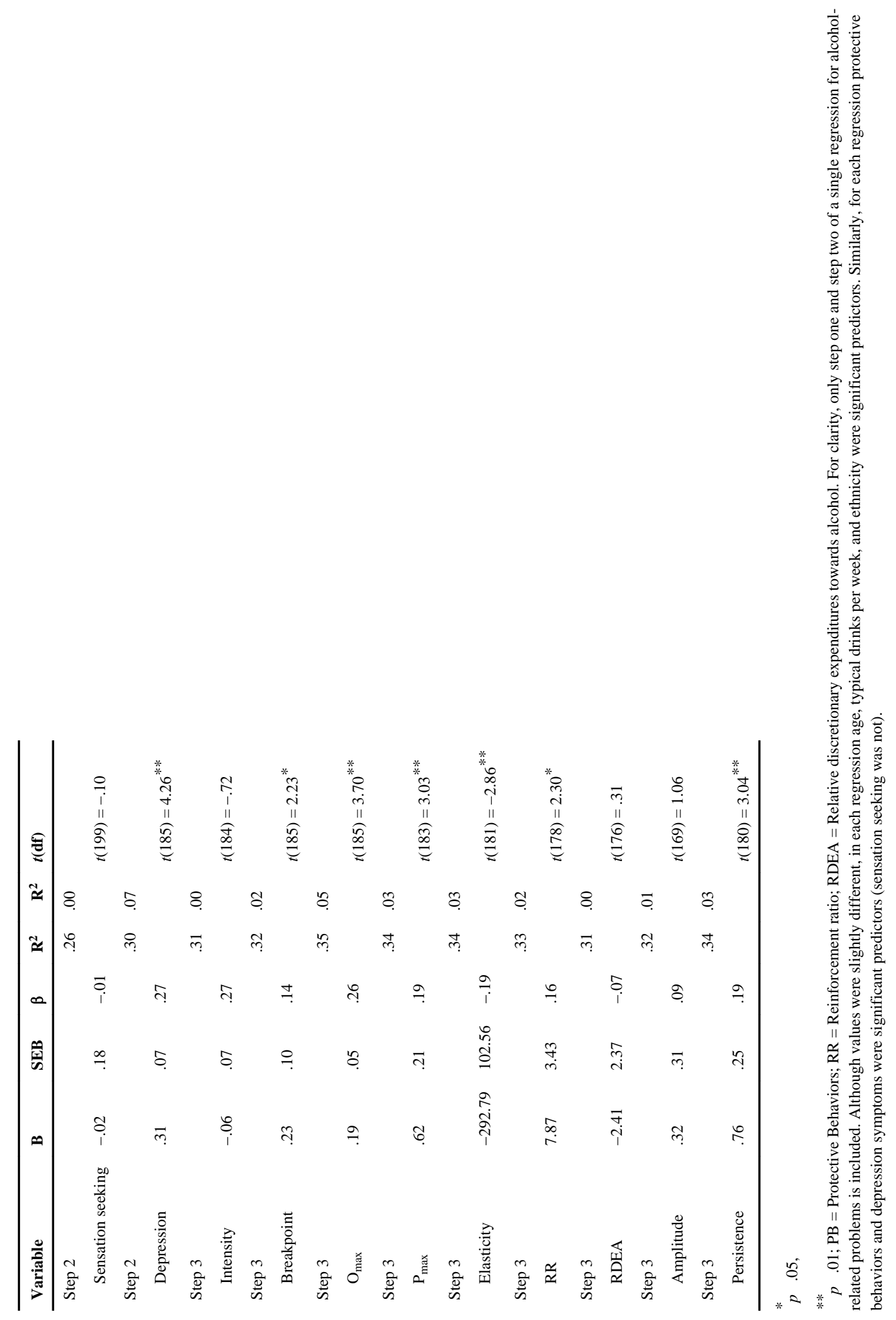

